\title{
ARAHAN PENGEMBANGAN FUNGSI KAWASAN PELABUHAN RAKYAT SEBAGAI KAWASAN PELABUHAN WISATA DI DESA BOROKO KABUPATEN BOLAANG MONGONDOW UTARA SULAWESI UTARA
}

\author{
Muhammad Zaki ${ }^{1}$ \\ ${ }^{1}$ Jurusan Arsitektur Universitas Muslim Indonesia
}

\begin{abstract}
Abstrak
Kegiatan penataan bangunan dan lingkungan merupakan salah satu bagian yang penting dalam upaya menciptakan penataan ruang yang terpadu, dengan menciptakan aktivitas baru,lingkungan yang berkualitas, penataan permukiman yang terarah, dan kawasan sebagai bagian dari suatu ruang kota.

Tujuan dari pengembangan fungsi pelabuhan ini adalah mengembangkan potensi kawasan tepian pantai di desa boroko kabupaten bolaang mongondow dengan konsep pengembangan faslitas dan infrastruktur yang di sesuaikan dengan karakter dan kondisi lingkungan masyarakat dan mempertimbangkan asas perencanaa lingkungan yang berkelanjutan serta mengintegrasikan antara fungsi permukiman, prasarana transportasi dan aktivitas yang dapat menjembatani berbagai kegiatan komersial, fasilitas umum dan fasilitas sosial pada jalur lintas Provinsi.

Metode dan Arahan Pengembangan Fungsi Pelabuhan ini dilakukan menggunakan metode Deskriptif dan ditujukan untuk mewadahi kegiatan wisata pantai dan beberapa pulau wisata yang ada disekitar pelabuhan desa boroko diantaranya Pantai Batu Pinagut, Pulau Damar, Ayer Belanda, Pantai Tanjung Dulang. Hasil akhir penelitian ini melahirkan ide dan gagasan dengan pendekatan pengembangan kawasan binaan dengan analisis dan konsep arahan desain sebagai pengembangan destinasi wisata kabupaten bolaang mongondow
\end{abstract}

Kata kunci: Arahan Pengembangan, Pelabuhan Wisata, Kawasan Wisata terpadu

\begin{abstract}
Activity arrangement of buildings and the environment is one important part of the effort to create an integrated spatial planning, by creating new activities, environmental quality, targeted settlements, and the region as part of an urban space.

The purpose of the development of port functions is to develop the potential of the area to the shore in the village Boroko Bolaang Mongondow Regency with the development concept faslitas and infrastructure that are customized to the character and condition of community environment and consider the principles stats sustainable environment as well as to integrate the function of settlement, transport infrastructure and activities to bridge various commercial activities, public facilities and social facilities in the province traffic lane.

Methods and Function Development Tutorial This port is done using descriptive method and is intended to facilitate the activities of tourist beaches and islands around the harbor tourist villages such Boroko Batu Pinagut Beach, Damar Island, Ayer Belanda, Tanjung Dulang Beach. The final results of this study give birth to new ideas and with regional development approach guided by analysis and concept design direction as a travel destination development Bolaang Mongondow District.
\end{abstract}

Keywords: Development Tutorial, Travel Ports, Integrated tourism area

\section{PENDAHULUAN}

Kabupaten Bolaang Mongondow Utara merupakan salah satu daerah otonomi di Provinsi Sulawesi Utara yang secara geografis berada pada $0^{\circ}-30^{\prime}, 1^{\circ}-0^{\prime}$ Lintang Utara dan $123^{\circ} 01^{\prime} 26,4^{\prime \prime}$ Bujur Timur- $124^{\circ} 01^{\prime}$ 30,2" Bujur Timur. Luas Wilayah $185.686 \mathrm{Ha}\left(1.856,86 \mathrm{Km}^{2}\right), \pm 12,3 \%$ dari luas Provinsi Sulawesi Utara. Kabupaten Bolaang Mongondow Utara dilalui oleh jalan Trans Sulawesi dipesisir pantai utara Kabupaten Bolaang Mongondow Utaradimana jalan ini berfungsi sebagai jalur lalu lintas dari dan kedaerah Minahasa,
Manado dan Bitung disebelah timur dan Provinsi Gorontalo disebelah barat.

Salah satu kebijaksanaan pembangunan yang akan ditempuh dalam pembangunan Kabupaten Bolaang Mongondow utara adalah meningkatkan kualitas sumber daya manusia sebagai kekuatan utama pembangunan dan sekaligus sebagai modal dasar dalam upaya meningkatkan taraf hidup dan kesejahteraan masyarakat. Sedangkan pembangunan dalam bidang ekonomi yang merupakan prioritas utama pembangunan daerah tetap akan diupayakan semaksimal mungkin atau sedemikian rupa melalui sektor perdagangan, industri dan jasa, untuk 
dijadikan sebagai lokomotif dalam meningkatkan pembangunan.

\section{ISI PENELITIAN}

\subsection{Metode Penelitian}

Penelitian ini merupakan penelitian kualitatif yang bersifat Deskriptif dengan metode pengumpulan data yang dilakukan dengan survei primer melalui pengamatan dan menggunakan analisis SWOT yang merupakan metode analisis perencanaan strategis yang digunakan untuk mengevaluasi kekuatan (strengths), kelemahan (weaknesses), peluang (opportunities), dan ancaman (threats), serta survei sekunder dengan kajian literatur dokumen instansi, pustaka buku, dan penelusuran data online. responden penelitian ditentukan dengan teknik observasi lapangan dan melalui wawancara dan analisa stakeholder untuk mendapatkan sejumlah informasi kunci yang kompeten dan berpengaruh dalam pencapaian tujuan akhir penelitian ini. Stakeholder kunci (responden penelitian) dalam penelitian ini antara lain :

1. BAPPEDA Kabupaten Bolaang Mongondow Utara

2. Dinas Cipta Karya dan Tata Ruang Kota Bolaang Mongondow Utrara

3. Dinas Perhubungan Kabupaten Bolaang Mongondow Utara

4. Dinas Bina Marga Kabupaten Bolaang Mongondow Utara

5. Dinas Pertanian dan Perkebunan Kabupaten Bolaang Mongondow

\subsection{Issue dan Permasalahan}

Pusat kota Kecamatan Kaidipang berada di desa Boroko dengan sebagian besar memiliki kepadatan bangunan yang Rendah dan memiliki pola jalur jalan yang lebih banyak dan layak digunakan untuk kendaraan ringan dan jarak dekat. Kegiatan di kawasan pelabuhan rakyat di dominasi oleh kegiatan bongkar muat hasil tangkapan nelayan. Namun dalam pengembangan perencanaan kawasan pelabuhan nelayan akan memiliki wilayah pengembangan yang baru. Hal yang perlu menjadi perhatian pada pengembangan kawasan ini adalah pembangunan fasilitas infrastruktur yang berfungsi sebagai penunjang kegiatan di kawasan pelabuhan wisata, karena wilayah perenelitian ini merupakan pusat kota kecamatan yang dilalui oleh jalur jalan trans Sulawesi sehingga hal inilah yang menjadi salah satu issue dalam pengembangan kawasan pelabuhan rakyat menjadi kawasan pelabuhan wisata

Pelaksanaan pembangunan Kabupaten Bolaang Mangondow juga perlu mempertimbangkan aspek yang sangat krusial yaitu manajemen pembangunannya, baik berupa perencanaan, pengorganisasian, penggerakan motivasi para pelaku pembangunan dan pengontrolannya. Sehingga dalam penelitian perencanaan kawasan pelabuhan wisata ini dapat menghasilkan destinasi wisata baru.
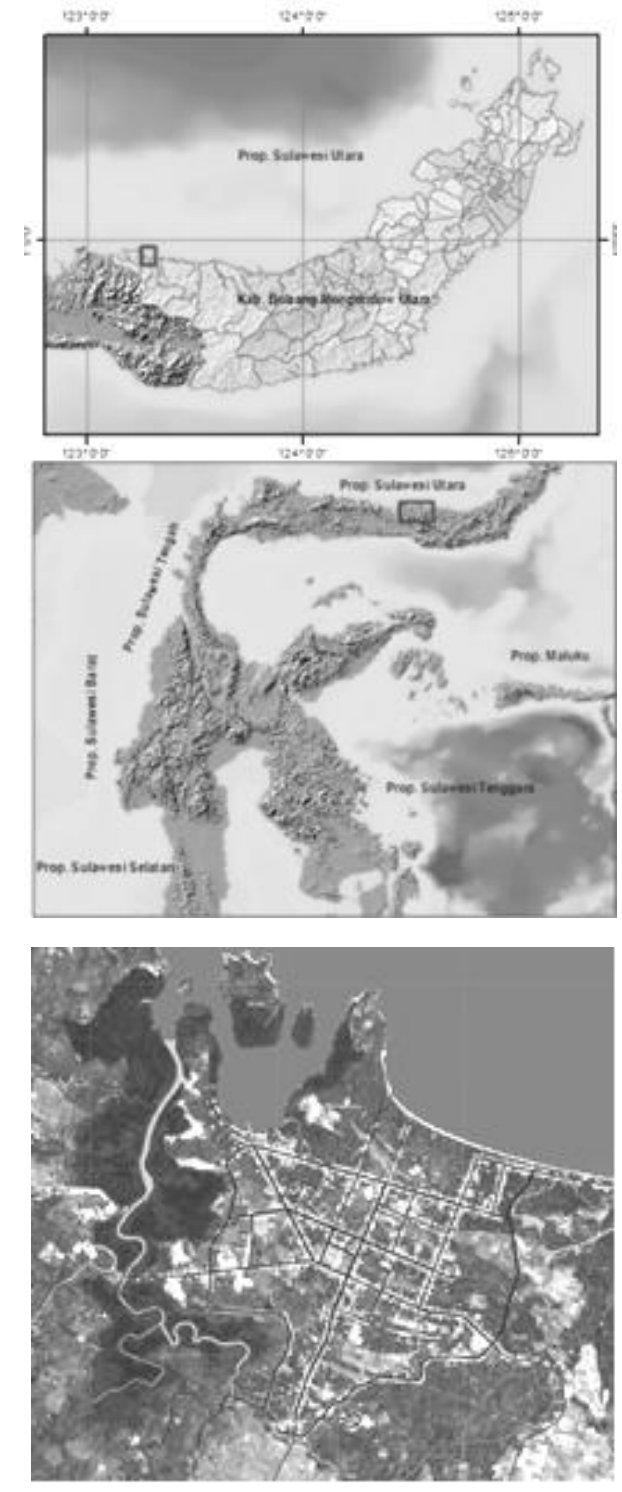

Gambar : Foto Udara Citra Satelit Kabupaten Bolaang Mongondow Utara, 2015

Sumber : Analisis 2015

Sistem drainse juga perlu menjadi perhatian agar sesuai dengan kebutuhan daya alir dilingkup masyarakat sekitar kawasan pelabuhan, terutama yang perlu diperhitungkan pada saat hujan lebat yang bersamaan dengan air pasang mengingat pada wilayah ini masih rentan terhadap banjir.

Berdasarkan hasil analisis data curah hujan yang tersebar di wilayah wilayah Bolaang Mongondow Utara, tipe iklim wilayah bervariasi yakni daerah basah dengan vegetasi masih hutan hujan tropika hingga agak kering.

Kawasan penelitian ini memeiliki intensitas bangunan masih sangat kurang. Bangunan-bangunan hanya terdapat pada sepanjang jalan trans Sulawesi. Pada daerah persimpangan jalan, bentuk bangunanbangunan mengikuti arah lengkung jalan. Sebagian besar bangunan yang ada masih mempertahankan bentuk bangunan Aslinya dengan mempergunakan elemen-elemen warna yang lembut, namun masih 
sudah ada sekitar $15 \%$ yang merupakan bangunanbangunan Modern. Balkon untuk bangunan yang memiliki lantai lebih dari satu biasanya berorientasi ke jalan dengan sempadan bangunan sekitar 0-3 meter.

\begin{tabular}{|c|c|c|c|c|}
\hline No & Nama Jalan & Jumlah Lantai Rata-Rata & KDB (\%) & KLB \\
\hline 1 & Jl. Trans Sulawesi & 1 & 70 & 1 \\
\hline 2 & Jl. Lingkar Pelabuhan & 1 & 75 & 1 \\
\hline & $\begin{array}{c}\text { Koefisien I } \\
\text { Bangunan } \\
\text { Wisata Desa }\end{array}$ & $\begin{array}{l}\text { Bangunan dan } \\
h \text { Perencanaan Ko } \\
\text { ko }\end{array}$ & efisien & $n$ \\
\hline
\end{tabular}

\subsection{Hasil Pembahasan}

Kegiatan intensitas pemanfaatan ruang merupakan pedoman dalam perencanaan penelitian kawasan pelabuhan wisata di desa boroko kabupaten bolaang mongondow ini dengan berdasarkan Koefisien Dasar Bangunan (KDB) yang di tujukan untuk mengatur proporsi antara daerah terbangun dengan tidak terbangun serta mengatur intensitas kepadatan bangunan; Koefisien Lantai Bangunan (KLB) merupakan ukuran yang menunjukkan proporsi total luas lantai semua bangunan dengan luas kavling di mana bangunan tersebut berdiri; dan Pengaturan ketinggian bangunan (skyline) yang diterapkan dalam penelitian ini bertujuan untuk Menciptakan ritme kesan visual yang indah, pemanfaatan lahan seefektif dan seefisien mungkin dengan mempertimbangkan daya dukung lahan, daya tampung lahan di kawasan pelabuhan, dan menciptakan keserasian bangunan dan pemandangan di sekitarnya sehingga menghasilkan men skyline kota dan kawasan yang serasi dan berkarakter.

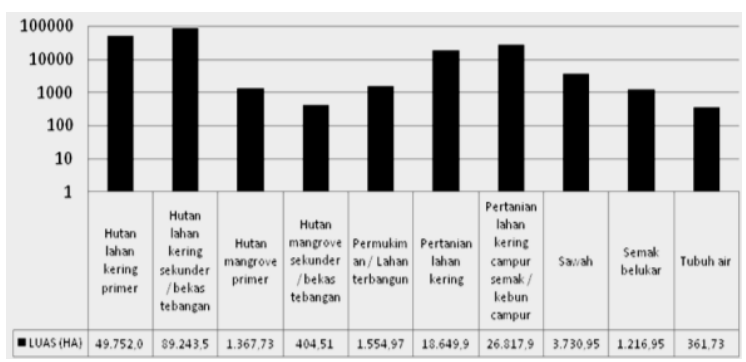

Tabel : Luas Masing Masing Jenis Penggunaan Lahan

Sumber: RTRW Kabupaten Bolaang Mongondow Utara, 2013

\subsubsection{Zonasi dan Peruntukan Lahan}

Secara umum dalam konsep peruntukkan lahan akan dibagi atas 3 (tiga) zona yaitu Zona 1,2 dan Zona 3 Berdasarkan pada konsep pengembangan fungsi kawasan, maka rencana peruntukkan lahan di masing-masing zona akan diarahkan sebagai berikut

\section{a. Zona 1 :}

Zona 1 pada kawasan ini adalah Kawasan inti perencanaan tata bangunan dan lingkungan kawasan Pelabuhan Wisata Desa Boroko Kabupaten Bolaang Mongondow Utara.

b. Zona 2 :

Fungsi utama dari zona ini adalah pengembangan desa wisata dan permukiman yang menyangga aktifitas inti di kawasan pelabuhan wisata dan mengembangkan potensi-potensi keragaman dan kreatifitas masyarakat setempat khususnya di desa boroko.

c. Zona 3 :

Zona ini merupakan sebagai zona fungsi penunjang kawasan inti yaitu zona campuran yang diperuntukkan sebagai wilayah penyeimbang perekonomian dan permukiman disekitar kawasan inti pelabuhan wisata.

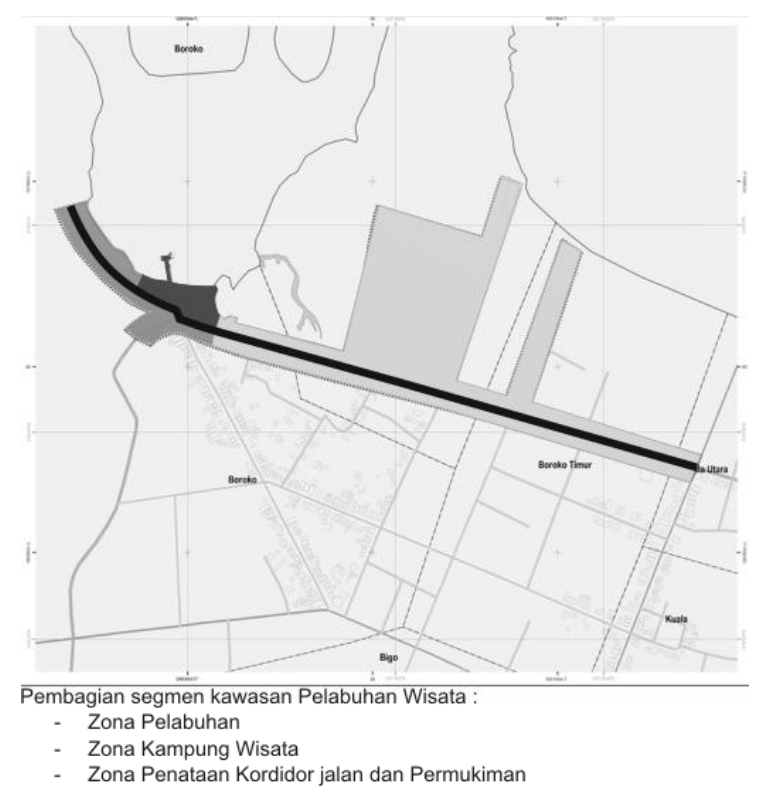

Gambar : Konsep zonasi dan figure ground kawasan, 2015

Sumber : Analisis 2015

Rencana perpetakan di kawasan penelitian, ditetapkan bervariasi sesuai dengan panjang persil ke belakang atau panjang blok. Sebagaimana rencana penggunaan lahan dan zonasi maka di kawasan ini ada beberapa sistem perpetakan yang akan dikembangkan, yaitu:

1. Blok Komersil

2. Blok permukiman/kampung wisata

3. Blok Faslitas umum dan Fasilitas sosial

\section{FIGURE GROUND}

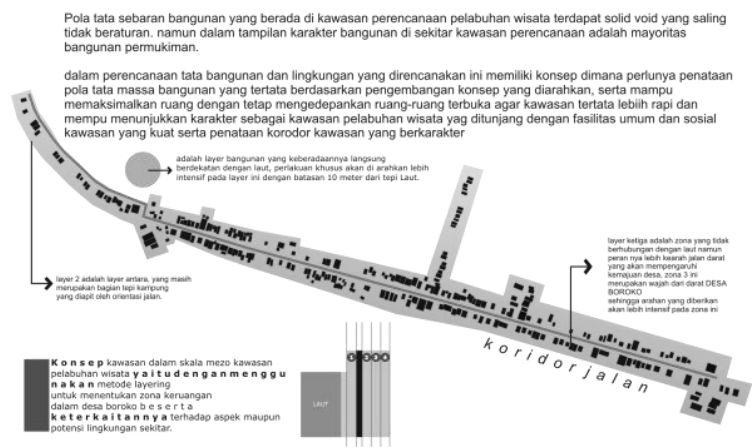

Gambar : Konsep zonasi dan figure ground kawasan, 2015 Sumber : Analisis 2015

Rencana tapak dan perpetakan pada masing-masing blok dan sistem kapling akan dikembangkan berdasarkan wilayah penunjang kawasan pelabuhan wisata, diantaranya adalah : 
a. Tapak dan Perpetakan di Blok Komersil

Rencana tapak dan perpetakan pada blok ini, secara umum mengikuti aturan/ketentuan yang ada yaitu:

- Dengan KDB 80\% maka luas kawasan non terbangun yang ada maksimal adalah $80 \%$ luas lahan.

- Petak bangunan dapat menempel pada batas kapling, hal ini dikarenakan di kawasan ini yang ditonjolkan adalah etalase yang menjadi tempat pajangan barang-barang dagangan.

Dengan melihat garis sempadan bangunan (GSB) yang sempit maka di sekitar blok ini pada tapak dan perpetakannya tidak dapat mengakomodasi penyediaan parkir.

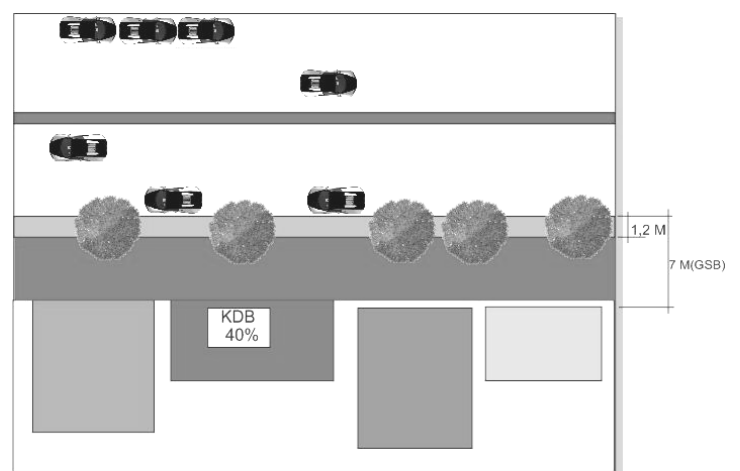

Gambar : Pola Tapak area Blok Komersil Sumber : Analisis 2015

b. Tapak Permukiman/kampong wisata

Perpetakan area rumah tinggal/permukiman terbagi menjadi rumah tradisional masyarakat Bolaang Mongondow Utara dan rumah non tradisional. Untuk rumah tradisional disesuaikan dengan kaidah arsitektur tradisional Bolaang Mongondow Utara yang diarahkan sebagai permukiman wisata. sedangkan untuk rumah non tradisional direncanakan sesuai dengan aturan/ketentuan yang berlaku yaitu berdasarkan RTRW Kabupaten Bolaang Mongondow Utara tentang Ketentuan Sempadan Bangunan.
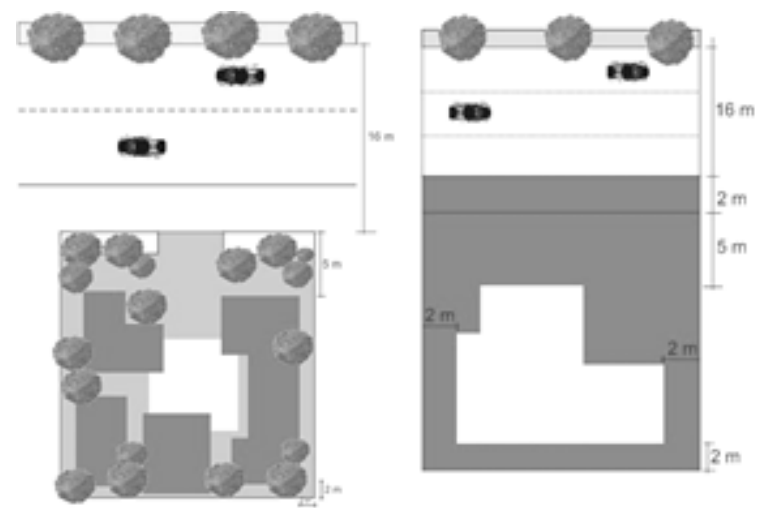

Gambar : Pola Tapak area Blok Permukiman Sumber : Analisis 2015

Hal ini di arahkan agar kawasan pelabuhan wisata dapat memiliki kesan yang saling mendukung dalam keselarasan konsep perencanaan agar dapat terciptanya pemerataan di sekitar wilayah penelitian perencanaan kawasan pelabuhan wisata di desa boroko. Dengan demikian konsep pengembangan akan sejalan dengan system pola pemeataan dan berkelanjutan.

c. Tapak dan Perpetakan Pada Fasilitas Umum dan Fasilitas Sosial

Tapak dan perpetakan untuk Fasilitas Umum dan Fasilitas Sosial disesuaikan dengan aturan/ketentuan bangunan yang telah ditetapkan dalam RTRW Kabupaten Bolaang Mongondow Utara tentang Ketentuan Sempadan Bangunan dan rencanana pengembangan kawasan pelabuhan rakyat menjadi kawasan pelabuhan wisata.
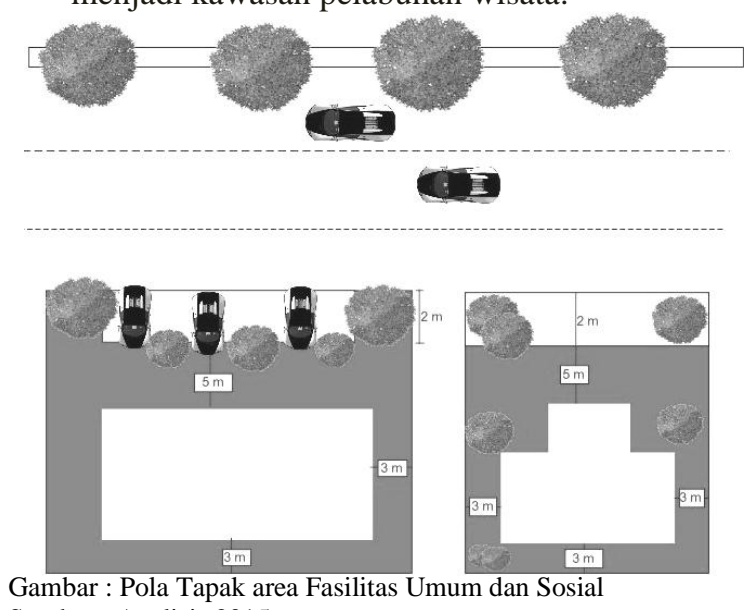

Sumber : Analisis 2015

\subsubsection{Sistem Sirkulasi dan Jaringan Jalan}

Rencana sistem pergerakan yang diteliti pada perencanaan kawasan pelabuhan wisata adalah mengatur sistem lalu lintas semua sarana intermoda termasuk didalamnya para pejalan kaki, sehingga dengan penataan sistem pergerakan diharapkan mampu mencerminkan tata lalu lintas yang terpadu yang bisa mengakomodasi setiap pergerakan yang menggunakan sarana jalan menuju ke kawasan pelabuhan wisata.

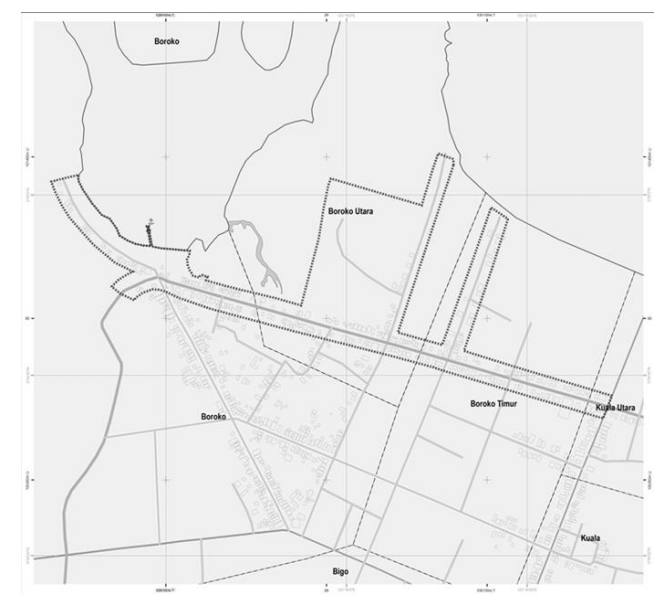

Gambar : Peta Jaringan Jalan Kawasan Pelabuhan Wisata Sumber : Survey \& Analisis 2015 
Jalan utama di kawasan perencanaan memerlukan penataan terutama guna mengoptimalkan fungsi jalan tersebut sebagai jalan antar provinsi selain itu untuk mengantisipasi permasalahan - permasalahan jalan, antara lain: kemacetan, keindahan/estetika, dan kenyamanan.

a. Koridor Sepanjang Jalan Lingkar/ Ringroad

Penataan jalan utama di jalan Lingkar adalah penataan jalan masuk ke kawasan Pelabuhan Wisata Desa Baroko dan rencana penataan kantongkantong parkir serta penataan pedestrian di sepanjang jalan utama yang padat akan aktivitas masyarakat.

b. Koridor Kawasan Pelabuhan Wisata

Koridor Kawasan Pelabuhan Wisata memerlukan penataan dan pembangunan Landmark Pelabuhan Wisata. Landmark Pelabuhan Wisata berupa tugu yang berada di dalam kawasan yang terletak pada jalan masuk kawasan.

c. Koridor Jalan Kolektor

Sesuai dengan rencana sistem jaringan jalan di kawasan perencanaan maka jalan Kolektor ini berfungsi sebagai jalan poros gerbang menuju Kawasan Pelabuhan wisata. Adapun perencanaan penataan geometrik jalan terlihat pada potongan melintang jalan kolektor tersebut,dimana bagianbagian jalan tersebut terdiri dari :
1) Damija
2) Lebar Lajur
16,00 meter
3) Jumlah Lajur
8,00 meter
4) Drainase Jalan
2 buah
0.70 meter

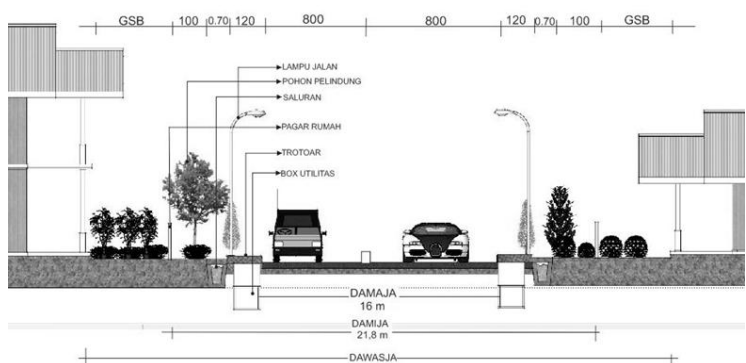

Gambar : Potongan Koridor Jalan Kolektor

Sumber : Analisis 2015

\section{d. Koridor Jalan Lingkungan}

Untuk rencana geometrik ruas jalan lingkungan Damaja 7,00 meter ini juga dapat dilihat pada gambar, dengan perinciannya sebagai berikut:
1) Damija
7,00 meter
2) Lebar Lajur
3) Jumlah Lajur
3,50 meter
2 buah
0,70 meter
4,00 meter
5) GSP/Telajakan
4,00 meter
6) GSB

Penerapan jalan koridor ini adalah diwilayah permukiman masyarakat desa boroko yang juga merupakan masuk dalam pengembangan permukiman wisata yang berorientasi pada konsep street community yang mengutamakan pejalan kaki sebagai pengguna jalan.

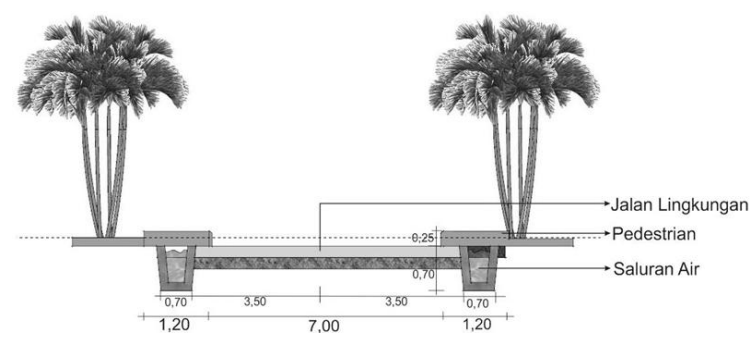

Gambar : Potongan Koridor Jalan Lingkungan

Sumber : Analisis 2015

\section{e. Jalur Pedestrian}

Fungsi fasilitas pejalan kaki yaitu memberikan kesempatan bagi lalu lintas orang, sehingga dapat berpapasan pada masing-masing arah atau menyalip dengan rasa aman dan nyaman, disamping itu untuk mengindari bercampurnya pergerakan antara pejalan kaki dengan kendaraan.

Fasilitas yang dibutuhkan tentu sesuai dengan bentuk pergerakan para pejalan kaki yang dikelompokkan menjadi pergerakan menyusuri jalan, memotong jalan dan pergerakan di persimpangan. Sesuai dengan kebutuhan fasilitas pejalan kaki pada kawasan perencanaan dapat berupa trotoar, zebra cross serta pergerakan di persimpangan.

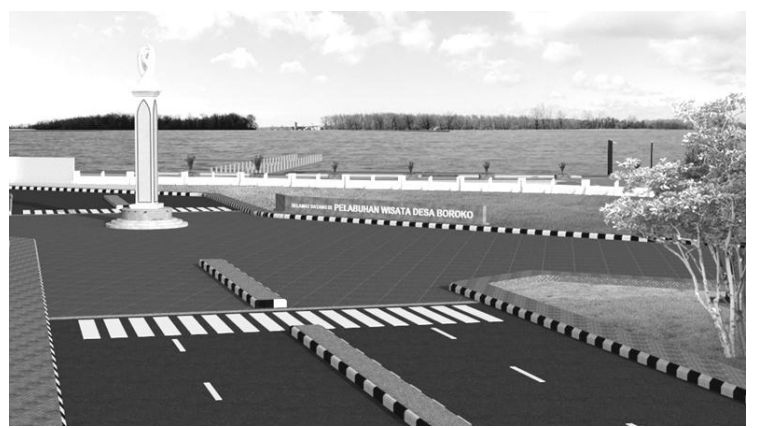

Gambar : Arahan Penataan Jalur Pejalan kaki dan zebra cross Sumber : Konsep \&Arahan Desain, 2015

\section{f. Sistem Perparkiran}

Kondisi kemacetan pada kawasan perencanaan belum terlalu menjadi masalah mengingat intensitas kendaraan yang masih relatif kurang. Namun kondisi parkir pada ruas jalan yang relatif rawan menimbulkan kemacetan terutama pada saat beroperasinya pelabuhan wisata di Desa Boroko, dimana pada waktu tersebut intensitas volume arus lalu lintas kendaraan menjadi meningkat cukup drastis, diakibatkan meningkatnya jumlah penumpang dan dan para pengunjung pelabuhan wisata.

Penataan parkir disekitar kawasan wisata,yang dimana dimaksud adalah Pelabuhan Wisata di Desa Boroko maka yang diperlukan adalah penataan site untuk parkir,dimana area parkir berada diluar kawasan (on street parking). Ini dikarenakan lahan pelabuhan wisata yang tidak memungkinkan diadakannya area parkir. 


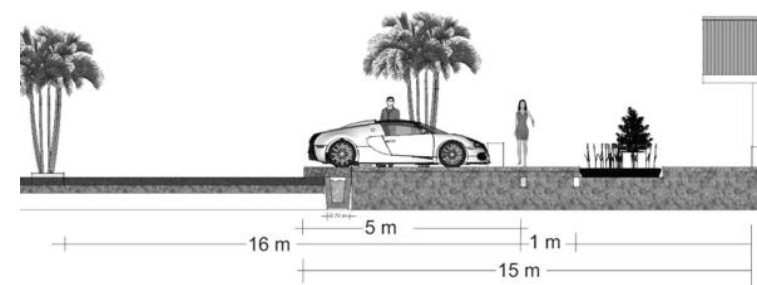

Gambar : Arahan Penataan Jalur Pejalan kaki dan zebra cross Sumber : Konsep \& Arahan Desain, 2015

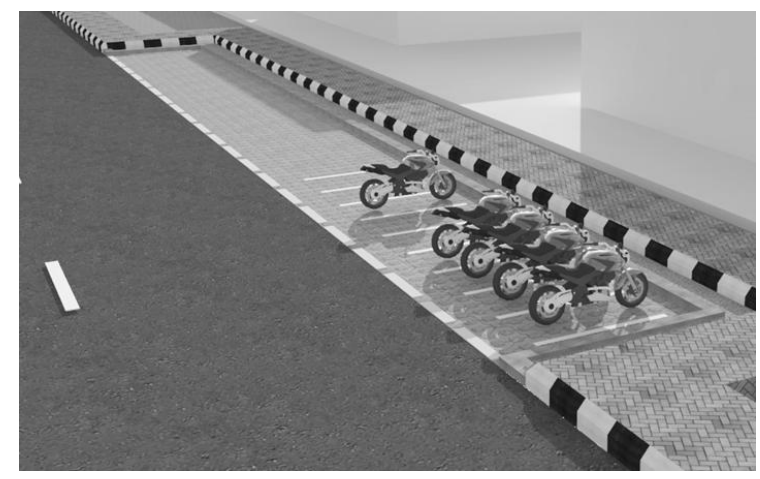

Gambar : Arahan Penataan Kantong-kantong Parkir Sumber : Konsep \& Arahan Desain, 2015

penataan parkir disekitar kawasan wisata,yang dimana dimaksud adalah Pelabuhan Wisata di Desa Boroko maka yang diperlukan adalah penataan site untuk parkir,dimana area parkir berada diluar kawasan (on street parking). Oleh sebab itu penataan parkir pada badan jalan dapat dilaksanakan juga dengan cara memundurkan trotoar sejauh 4 meter dengan asumsi satu blok $4-5$ kendaraan sehingga on street parking ini tidak akan mengganggu kelancaran arus lalu lintas di sekitar jalan raya tersebut.

Kelebihannya:

1. Kenyamanan dan keamanan kegiatan parkir di kawasan ini akan lebih meningkat;

2. Estetika kawasan menjadi lebih tinggi;

3. Arus lalu lintas kendaraan akan lebih lancar.

\section{Kelemahannya:}

Pembebasan lahan di sekitar kawasan ini akan mendapat kesulitan karena kondisi kawasan yang relatif padat permukiman masyarakat.

\section{g. Sistem Drainase}

Sebagian besar wilayah perencanaan menggunakan drainase, hanya pada jalan lingkungan yang tidak memiliki drainase. Oleh karena itu diperlukan pembuatan dan penataan jaringan drainase pada beberapa jalan di kawasan perencanaan. Adapun rencana penataan jaringan drainase pada wilayah perencanaan adalah sebagai berikut:

1. Jalan Kolektor :

- Perbaikan dan pemeliharaan jaringan pembuangan sekunder (got).

- Pembuatan ramp pada masing-masing kavling yang dilengkapi dengan tali air.
- Berupa saluran tertutup dengan lebar 0,70 m merupakan satu kesatuan dengan jalur pejalan kaki.

- Jaringan drainase tetap pada posisi kondisi saat ini hanya saja dilakukan perbaikan kondisi saluran dan pembuatan jaringan drainase pada jalan yang belum memiliki drainase yang merupakan saluran pembuangan air hujan dan limpasan air hujan dari jalan raya.

2. Jalan Lingkungan:

Pembuatan jaringan pembuangan sekunder (got). Berupa saluran terbuka dengan lebar 0,50 $m$ merupakan saluran pembuangan air hujan dan limpasan air hujan dari jalan raya.

Berdasarkan rencana penataan jaringan tersebut maka beberapa rancangan sistem drainase yang akan dikembangkan di kawasan perencanaan adalah Bentuk got/saluran drainase yang direncanakan untuk dikembangkan adalah pada saluran tertutup sebaiknya berbentuk kotak dengan sistem pre-cast sedangkan untuk saluran terbuka berbentuk trapesium.

\subsection{Arahan Pengembangan Kawasan Pelabuhan Wisata di Desa Boroko}

Dari hasil penelitian potensi pengembangan kawasan pelabuhan di desa boroko memiliki peluang yang besar, itu dapat ditandai mengenai adanya beberapa destinasi-destinasi yang berhubungan dengan kawasan pelabuhan wisata yang akan menjadi tujuan destinasi baru apabila dalam penyusunan penelitian ini mampu memberikan masukan dan arahan pengembangan di dalam meningkatkan sumber kunjungan wisata lokal maupun mancanegara.

Selain potensi daya tarik wisata ada beberapa permasalahan yang ada disekitar kawasan guna dalam rangka penyesuaian dalam menentukan ide dan gagasan dalam menjadikan kawasan pelabuhan rakyak ini menjadi kawasan pelabuhan wisata yang perlu dijawab antara lain :

a. Arahan dalam pengaturan kegiatan nelayan dalam bongkar muat hasil tangkapan.

b. Arahan Pembangunan Infrastruktur di kawasan pelabuhan wisata.

c. Arahan Sistem Drainase di area kawasan dan di sekitar kawasan.

d. Arahan elemen-elemen penguat karakter kawasan

e. Arahan penataan system pola parkir aktifitas di sekitar kawasan pelabuhan wisata

f. Arahan penataan permukiman yang diusulkan sebagai permukiman wisata.

Dengan mengambil pertimbangan dari 6 permasalahan yang ada pada kawasan penelitian dalam rangka untuk mengarahkan kawasan pelabuhan rakyat menjadi pelabuhan wisata diperlukan arahan konsep yang akan dijadikan sebagai landasan dalam proses tahapan perencanaan 
selanjutnya akan menjadi acuan dalam menentukan tema alur dan desain dalam kawasan pelabuhan wisata, hasil dari wawancara dari berbagai dinas dan masyarakat yang dianggap sebagai salah satu informasi dan masukan yang dianggap penting untuk ditindak lanjuti sesuai dengan kebutuhan intasnsi pemerintah dan masyarakat sekitar kawasan pelabuhan wisata yaitu diantaranya :

1. Pembangunan pengembangan dermaga yang mampu di akses oleh kendaraan pengambil hasil tangkapan ikan yang akan terus disalurkan keapda penyalur. Menyediakan fasilitas ruang pendingin ikan yang dimanfaatkan sebagai ruang penyimpanan sebagian hasil tangkapan nelayan.

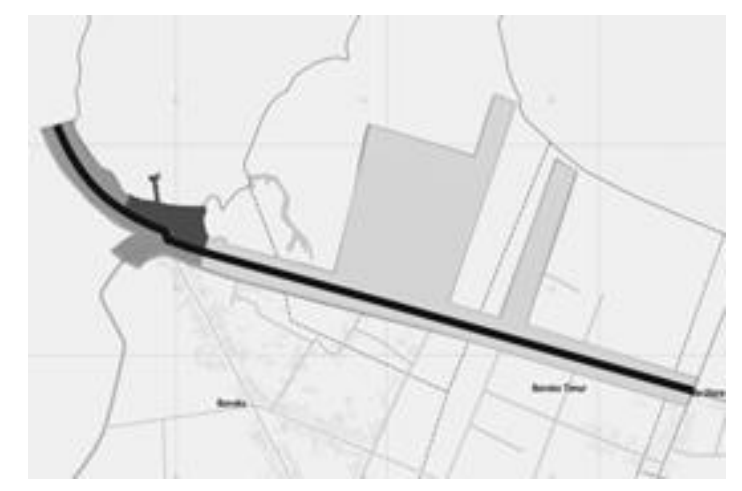

Gambar : Arahan Deliniasi Perencanaan

Sumber : Konsep \& Arahan Desain, 2015

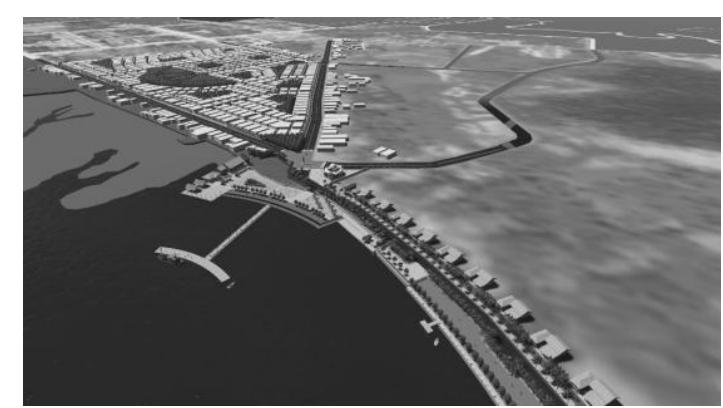

Gambar: Arahan perencanaan pengembangan dermaga wisata Sumber : Konsep \& Arahan Desain, 2015

2. Menyediakan fasilititas kantor pengelola dikawasan pelabuhan wisata yang menjadi pusat kegiatan dan informasi segala aktifitas baik mengenai nelayan dan kegiatan wisata pantai didaerah kabupaten Bolaang Mongondow Utara.

3. Merencanakan sistem drainase di area kawasan dan disekitar kawasan pelabuhan wisata meliputi sektor permukiman masyarakat dan area penunjang (komersil), sehingga permasalahan genangan air yang sering didapatkan dimusim penghujan dapat diatasi seminimal mungkin.

4. Kegiatan peremajaan area mangrove yang tumbuh disekitar kawasan pelabuhan wisata yang diarahkan sebagai jangkar pemecah ombak alami dan sebagai bentuk kepedulian dalam menjaga ekosistem yang ada disekitar kawasan pelabuhan wisata.

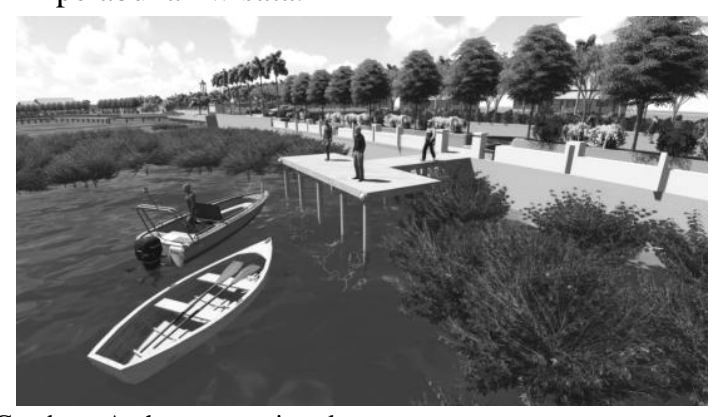

Gambar : Arahan peremajaan kawasan mangrove

Sumber : Konsep \& Arahan Desain, 2015

5. Perencanaan pembangunan landmark Kawasan yang berfungsi sebagai penanda aktifitas pada kawasan.

6. Penetapan perencanaan elemen-elemen pembentuk kawasan yang berfungsi untuk mempertegas fungsi dan karakter kawasan agar mampu menjadi icon di kawasan Pelabuhan WIsata di desa boroko.

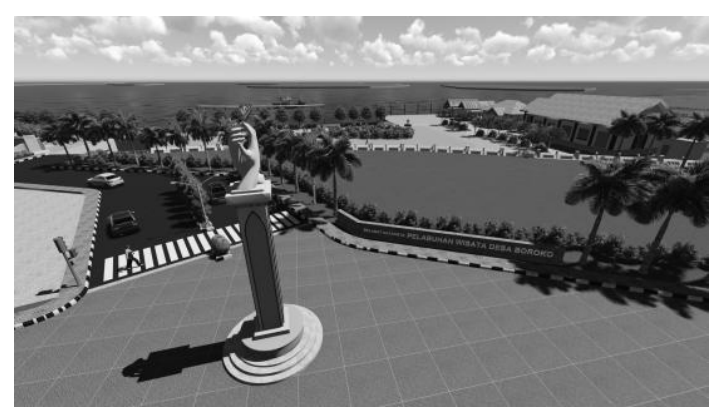

Gambar : Arahan perencanaan landmark Kawasan Sumber : Konsep \& Arahan Desain, 2015

7. Penentuan dan pembangunan sistem area parkir dan kantong-kantong parkir disepanjang area deliniasi kawasan yang telah ditentukan agar dapat mengantisipasi peningkatan jumlah pengunjung di kawasan pelabuhan wisata dihari dan waktu tertentu.

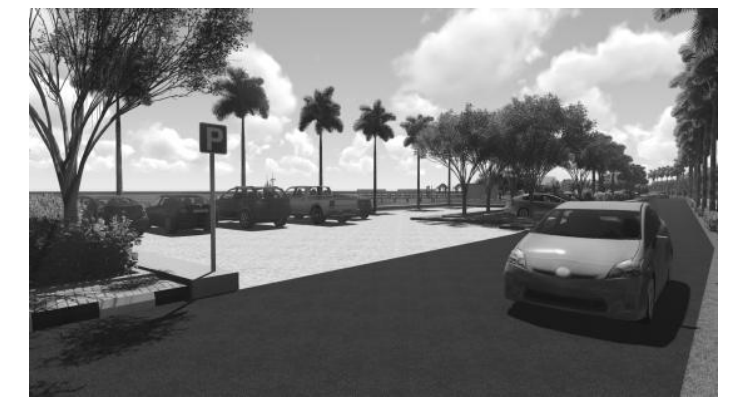

Gambar : Arahan perencanaan landmark Kawasan

Sumber : Konsep \& Arahan Desain, 2015

8. Penyediaan sarana prasarana transportasi darat dan laut sebagai moda wisata internal yang melayani pergerakan wisatawan, seperti perahu 
katinting, becak wisata, sepeda wisata, bus dan halte wisata, taman bermain anak, dan lainnya.

9. Arahan pola penataan tinggi rendahnya (skyline) bangunan agar tidak terjadi kesemrawutan perencanaan apabila kawasan sudah masuk dalam pengembangan kebutuhan fasilitas dan area terbangun lainnya.

10. Menyusun sistem pola strategi manajemen kunjungan dalam rangka menaikkan citra kawasan pelabuhan wisata di desa boroko dengan menciptakan slogan promosi/identitas kawasan pelabuhan wisata, gerbang selamat datang, peta-peta penanda destinasi, papan informasi yang tentunya kesemuanya dapat memberikan kenangan dan kesan baik dari masyarakat dan wisatawan secara khusus.

\section{KESIMPULAN}

Dalam mendukung program kegiatan penelitian di Kawasan Pelabuhan Wisata Desa Boroko yang berkaitan dengan aktivitas perencanaan dan pemanfaatan ruang kawasan, kegiatan pengelolaan dan pengendalian kawasan harus menempati posisi yang sesuai dan dipandang penting untuk menjaga citra kawasan sebagai kawasan wisata.

Penyesuaian penelitian terhadap RTRW Kabupaten Bolaang Mongondow Utara, yaitu merupakan pembenahan fungsi peruntukan lahan sesuai dengan Rencana Tata Ruang Kabupaten Bolaang Mongondow Utara sebagai upaya untuk mengembangkan wilayah di sekitar kawasan perencanaan pelabuhan wisata. Hal tersebut terutama ditujukan pada bagian-bagian kawasan yang sudah terbangun. Bagian-bagian yang tidak sesuai dengan rencana tata ruang segera diberitahu mengenai hal ini dan agar mereka mengubah penggunaannya sesuai dengan rencana peruntukan. Pada kawasan perencanaan, proses penyesuaian terhadap dokumen-dokumen perencanaan tata bangunan dan lingkungan yang ada kemungkinan dapat di padukan dan masuk pada penerapan gagasan pada fasilitas pelabuhan wisata ,perdagangan dan jasa yang terdapat di sepanjang jalur kolektor kabupaten bolaang mongondow utara.

\section{DAFTAR PUSTAKA}

- Apridev K, Ema U, Arahan Pengembangan Kawasan Wisata Terpadu Kenjeran Surabaya, Jurnal Teknik POMITS Vol. 2, No. 1, 2013

- Rencana Tata Ruang Wilayah (RTRW) Kabupaten Bolaang Mongondow Utara, 2013

- Ranperda Rencana Detail Tata Ruang (RDTR) Kabupaten Bolaang Mongondow, 2013

- Rencana Tata Bangunan dan Lingkungan (RTBL), Kawasan Pelabuhan Wisata Bolaang Mongondow, 2015

- Sastrawati, Isfa. 2003. "Prinsip perancangan kawasan tepi air (kasus : kawasan Tanjung
Bunga)". Jurnal Perencanaan Wilayah dan Kota. Hal. 98. Vol 14 No. 3 